\title{
Computer education in developing countries: the Sudan case
}

\author{
Assim A. Sagahyroon \\ Northern Arizona University \\ Flagstaff, Arizona \\ USA
}

\begin{abstract}
In Africa the heady optimism of the independence years has given way to mounting international concern as the development process has faltered. In the education sector, despite the impressive achievements that have been made in educational systems in some African countries, the present situation provides little grounds for complacency. Symptoms of decline are evident throughout the continent. In many ways Sudan exemplifies the problems facing the continent. In recent years this nation has suffered from environmental disasters such as drought and desertification leading to famine in some parts of the country, political instability and its ramifications, and a civil war that has been going on for more than a decade. We address the impact of information technology, in particular computers, on the educational system in the Sudan. An attempt is made to analyze the situation and critical issues are discussed. We feel that these issues are common to a majority of the African countries.
\end{abstract}

Main conference themes: developing countries

Educational areas:

Study topics:

Secondary keywords: case studies, computing 


\section{INTRODUCTION}

In a continent characterized by tumult and change the persistent and seemingly insatiable public demand for formal education has been one fascinating constant. The abiding faith of African governments and individuals in education as a means of advancing economic and social well-being has been found to be well placed, since in the absence of other modernizing institutions schools have been found to have more profound beneficial implications than earlier recognized [1].

In Africa, the sentiment for computerization can best be summarized by quoting Professor F. H. Allotey, of Ghana's University of Science and Technology; he is quoted while speaking in Tanzania to top decision makers in that country:

"We paid the price for not taking part in the industrial revolution of the late eighteenth century because we did not have the opportunity to see what was taking place in Europe. Now we see that information technology has become an indispensable tool. We can no longer sit down and watch passively [2]."

In fact the Organization of African Unity in its meeting at Addis Ababa in 1981 took the view that information technology is essential to developing countries. The governments of the African countries knowing that they can no longer escape considering computers began to pursue that path and in some cases international organizations such as the World Bank required computers in their adjustment programs. Much has been done in the last few years and the stories of success and/or failure vary.

Computer education in its broadest term covers teaching about computers or use of computers, and teaching of other subjects with computers [3]. We will discuss the role of computers in the Sudan in a top-down approach, i.e. we will address computer utilization at the university level first and then we will investigate its role in secondary and primary schools, and vocational training centres. The presumed rationales will be analyzed. Our focus will be on the distinctive features unique to computers in education in a developing country like Sudan. The problems will be discussed and future prospects outlined.

\section{COMPUTERS IN HIGHER EDUCATION}

Rogers [3] defines diffusion as the process by which an innovation is communicated through certain channels over time among members of a social system. In the Sudan the students at the University of Khartoum, the most 
prestigious university in the country, were chosen to be the pioneers in introducing computer technology to the rest of society. In the 1970s a computer centre was erected. The hardware platform was a miniframe which supported a small number of multi-users. The idea was that this centre, as a separate entity, would provide computing services for the rest of the university. The software consisted of a few high language compilers such as BASIC and FORTRAN, an editor and simple application programs.

At the time the main components of the university were the colleges of Medicine, Engineering, Agriculture, Arts, Physical Sciences, Law, Business Administration and Economics, the School of Mathematical Sciences, College of Veterinary Science and the College of Education.

The Computing Centre was located on the main campus which includes all of the above colleges except Medicine, Agriculture, Veterinary Science and Education. These four colleges were located miles away from the main campus. This posed an immediate problem. The public communication network in Sudan suffers from many shortcomings which make it unsuitable for data communication. Therefore accessing the central computer remotely was impossible. As an oil importing country Sudan experiences frequent shortages in gasoline and thus inadequacy of public transportation, or inflation in the prices of gasoline and public transportation; therefore we can easily exclude a high number of the population of these four colleges, professors and students together, from being able to gain from this centralized approach. Of the remaining colleges only a few made use of this new technology available at their doorsteps. The predominant users were the School of Mathematical Sciences and the College of Engineering. Of these two the former had a better chance to expose its students to computers, due to the fact that it was a smaller college than engineering and had less students per class. This made it possible for them to benefit from the multi-user environment provided by the centre.

In Engineering students were first exposed to computer programming in their second year of a five-year program (first year of general sciences and four years in the college of engineering). There are usually about 200 students in the programming lecture. This number encompasses students from the different disciplines of engineering (electrical, mechanical, civil, chemical and survey). With the limited resources available it was not feasible to provide all these students with hands-on training. Thus they were taught the fundamentals of problem solving using languages such as ALGOL and FORTRAN, while the programming was done on a pencil and paper basis. This was and continues to be a frustrating fact to most of them. In the final years the few who chose senior projects requiring programming, would then have access to the centre's facilities and would gain hands-on experience. A few professors were supervising research oriented MSc programs which required simulation and 
extensive statistical analysis. Hence an additional, but small number of graduate students made use of the centre.

The shortcomings of this centralized approach can be summarized as follows:

- The need for computerization in higher education was acknowledged, but no formal structures to promote, coordinate and assist in the adoption of computers were established.

- The shortage of qualified and trained personnel such as programmers, system analysts and technicians which were required to operate computer based systems.

- The process of adoption of this new technology lacked the necessary formal structure aforementioned; thus among the educators, specifically in the humanities oriented colleges, there was no perception as to how computers could be used to enrich the existing curriculum and improve the way in which it is delivered, by using computers as sophisticated educational tools which can extend traditional ways of presenting information.

- Some of the professors in the various colleges were not ready to adopt this new technology. Most of them had not received adequate training, including hands-on experience. Hence they were not ready to change their roles, some of them because of the erroneous assumption that computers challenge the traditional roles of teachers or others merely to assert that computers are irrelevant to proper education.

- In the case of Applied Sciences Colleges, like Engineering, the benefits which can be acquired through the introduction of computers were understood, but the limited resources provided by the centre (about 16 terminals to serve the whole university) made it impossible to provide the students with the needed training and experience. Evidence shows that problem solving skills using computers can only be enhanced by making this powerful tool accessible to students.

- The telecommunication infrastructure did not provide the services required to use the computer centre efficiently.

Since independence the governments of Sudan, in order to Sudanize the higher education, have taken the approach of sending the top graduates from the University of Khartoum to pursue their postgraduate studies in Europe and the USA When the third-fourth generations of these scholars from various fields began to return in the mid eighties after completing their $\mathrm{PhD}$ programs, they brought with them needed knowledge in computers and other relevant information systems. By this time the miniframe at the centre was obsolete due to the limited capabilities of the operating system and processors, and the 
limited capacity of the memory; in addition small but powerful machines began to emerge.

A policy of decentralization was adopted and the different departments went on their own ways to secure personal computer laboratories for their students through governmental funds when available, or from private donors. By this time the computer literacy curve among students, faculty and staff was rising slowly with time due to the following:

- The decentralization philosophy made these machines more easily accessible to students at their different departments.

- The returning scholars were enthusiastic to put computers to use in their curriculum directly or indirectly.

- The spread of vocational training centres which offered short courses in application programs and introductory programming classes.

- Students with relatives working in the rich Arab countries, such as Saudi Arabia, often had the luxury of having their own PCs provided by their relatives.

- Some administrators realized the potential of applying computers to various aspects of their administrative duties.

In addition an appreciable leap forward was made by the School of Mathematical Sciences by offering a degree with emphasis on computer science. A variety of courses in software and hardware were offered. The laboratory platform consisted mainly of X86 personal computers. In 1990 an educated entrepreneur who is also an authorized distributor of International Business Machines (IBM) equipment in Sudan, started a private four-year college with the promise of offering degrees in Computer Science, Computer Information Systems and Computer Engineering. Also training centres with commercial rationale spread throughout the big cities of the Sudan and mainly in the capital Khartoum. Even though many of these indicators reflect an optimistic view, the truth is that the future of computers in education is still beset with problems and difficulties. An attempt is made in a later section of this article to address these problems.

\section{COMPUTERS IN SECONDARY SCHOOLS}

Carnoy [4] proposed four levels of student access to computers in industrial countries. The relevance of these levels to the educational system in the developing countries was discussed in [3]. There Hawkridge concludes that there are very few instances of Level 1 (the highest) access in the developing 
countries. Level 2 prevails in selected secondary schools and Level 3 is the most common:

"Level 4 assumes that students must travel a substantial distance if they want access to a computer, therefore they hardly ever use one, perhaps only once in their entire schooling. It does not help students that the computer has good software, or that there is an able advisor present."

Hawkridge [3] reported that Level 4 does not prevail in the developing countries they investigated. If we shied away from defining a lower level (Level 5) to describe the situation in the Sudan, then we can easily conclude that Level 4 is the prevailing level in that country. Except for three to four private and thus expensive schools computers do not exist in most of the junior and high level schools in that nation. An enthusiastic instructor might form a computer club in a high school and solicit money or donations to acquire a personal computer for the club, but other than that there are no formal means and to the author's knowledge no future plans by the Ministry of Education to introduce computers into the system. Most of the time the only chance for a secondary school student to acquire hands-on experience with computers is to be in one of the large cities and be able to afford joining one of the commercial training centres. At the primary level there is none whatsoever worth mentioning.

\section{PROBLEMS FACING THE PROSPECTS OF COMPUTERS IN EDUCATION}

The greatest barrier of all which seems to stagnate and limit the spread of computer education in the Sudan, is the shortage of trained personnel. Few developing countries are capable of keeping their trained technicians, programmers and system analysts; Sudan is not one of them. Ojulu [5] reported in 1988 that about 60 percent of the qualified Sudanese leave to work in rich Arab countries. In recent years this percentage has increased and most of the professionals and skilled labour have left the country due to economics or politics. Those who stayed behind for various reasons, are left with very low morale. If we can argue that success or failure in using information technology depends more on the effectiveness of the teacher than the nature of the hardware or software used, then the future does not hold much hope for computers in education in that country.

To a great extent, the policy makers feel that the scarce foreign exchange should not be spent on importing computers. Since Ministers' decisions are influenced strongly by political, commercial and fiscal factors, we find that the Ministry of Education is playing a passive role in this issue. 
The other hurdles can be summarized as follows:

- The lack of a national policy geared toward the introduction of computers to the educational system with its different hierarchies.

- Computer literacy is low; it is usually acquired through training centres where making money is a priority and quality is a secondary concern.

- No cooperation exists among the few institutions which have some resources; thus in higher education computer systems are underutilized and duplication of effort is common.

- Sudan is the largest country in Africa covering an area of 2.5 million square kilometres; providing a reliable data communication network for the country is far beyond the available resources.

- The lack of a permanent and capable training resource.

- Customs barriers which impose heavy duties on imported hardware.

- Obsolescence-the rapid and genuine advances in computer technology render most of the existing hardware platforms obsolete in just a few years; in addition the chances of repairing a defunct computer are minute due to the lack of spare parts or trained technicians.

- The lack of standardization and local area networks-no connections exist between the different nodes and exchanging data or information remotely is not feasible which is frustrating for the more sophisticated users.

- The software needed to achieve proper application of computers in education is lacking; with the broad range of applications such as instructional software, simulation, CAD, CAM and administrative software, still software is imported on an individual level basis and most of the time a particular package will spread among computer users depending on who knows whom.

- The lack of a steady and predictable electric power supply.

\section{CONCLUSION AND RECOMMENDATIONS}

Regardless of priorities, assumptions, concerns or ideological positions about the future of computers in education in the Sudan one does not have to be an incurable pessimist to admit that there is still much left to be realized and the prospects of ten years ago are still largely unrealized. Theoretically the means of rectification are obvious, but we are confronted by a situation where economic change has to lead any possible educational change. Despite the possibility that Ministers of Education, and possibly their political and professional advisors as well, are likely to argue for the case of using computers as educational tools, we do not expect to see this movement 
flourishing in this decade. Deteriorating economies deny any state the resources needed for the development process. The government is preoccupied with quantitative expansion and concern for quality is becoming a secondary issue. International support has declined sharply effecting the regeneration of a qualified cadre equipped with the needed computer skills, while the brain-drain phenomenon is persistent. Despite all of these factors we humbly make the following recommendations:

- To narrow the gap between themselves and the developed world the governments of the developing countries should play an active role in spreading information technology. Ministries of education should take the lead in the demystification and provision of computers.

- Formation of a supporting base for this technology. This base should take the role of devising the policies, carrying the needed long-term planning, implementation and its prerequisites (e.g. awareness, education, training) and finally assessing the impact of this technology on the country. A major concern this base or group would be to find the financial justification for the investment required and to act as a resourceful, well-organized pressure group.

- The opportunity cost of computers is high where chalkboards, paper and textbooks and sometimes even food and water are in short supply [3]. International agencies and governments of the developed nations must make a commitment to offset this cost.

- The incorporation of incremental changes geared towards information technology in the educational system. The means and gradual integration of this technology into the curricula should be an important part of the longterm strategies.

- The private sector can easily be incorporated as a major player. The education sector might work with industry in identifying common areas of interest and hence enticing it to provide the financial component.

- Finally computerization must be perceived by decision makers as a means of improving efficiency. Since the case must be made for funding by the government, we feel that the simplest way is to organize short but effective visits and tours for these policy/decision makers to model countries from the developing world who have adopted this technology successfully.

It is doubtful that the new information technologies offer hopes of a breakthrough in the existing conditions of Africa. However these do hold the potential of complementing and enriching the present educational systems. The final word is left to the governments of the African nations, since they remain the prime movers in their nations' educational development. 


\section{REFERENCES}

1. Berg, R. and Whitaker, J., (eds.) (1986) Strategies for African Development. University of California Press.

2. Rwegayura, and Tanzania, A. (1988) A New Determination to Computerize. Computers in Africa, Jan-Feb.

3. Hawkridge, D., Jaworski, J. and McMahon, H. (1990) Computers in Third-World Schools. St. Martin Press.

4. Carnoy, Martin, Deley and Loop. (1987) Education and Computers: Vision and Reality. UNESCO.

5. Ojulu, E. (1988) Invasion by Micros Expands Market. Computers in Africa, Jan-Feb.

6. Giacquinte, J., Bauer, J., and Levin, J. (1993) Beyond Technology's Promise. Cambridge University Press.

7. Gleave, M., (ed.) (1992) Tropical African Development. Longman/J. Wiley and Sons. 